\title{
A COMPARISON OF THE INDENTATION SIZE EFFECT IN FUSED SILICA AND CRYSTALLINE QUARTZ
}

\author{
LEI ZHANG ${ }^{1}$ and RICHARD C. BRADT ${ }^{2}$ \\ ${ }^{1}$ Chemistry Department, Winston-Salem State University, Winston Salem, NC 27110 USA \\ Email: zhangl@wssu.edu \\ ${ }^{2}$ Department of Metallurgical and Materials Engineering, The University of Alabama \\ Tuscaloosa, AL 25487-0202 USA \\ Email:Rcbradt@eng.ua.edu
}

\begin{abstract}
The Indentation Size Effect (ISE) in Fused Silica and Crystalline Quartz were measured by both Knoop and Vicker indenters and both exhibited a crossover for the different indenters at about the same indentation load. The crossover can be explained by the ratio of the (surface area/indentation volume) from the geometries of the two indenters.
\end{abstract}

Key Words: Fused Silica; Crystalline Quartz; The Indentation Size Effect; Knoop; Vicker.

\section{INTRODUCTION}

Numerous testing techniques have been applied to study the mechanical properties of materials. Hardness measurement is an approach to estimate the strength of materials and indentation hardness methods, especially Vickers and Knoop microhardness indentation measurements, are among the most widely used approaches (Lysaght 1949; Berkovich 1951; Tabor 1951; Mott 1957; O'neill 1967; Westbrook and Conrad 1973; Blau and Lawn 1986). Vickers and Knoop indenters show the Indentation Size Effect (ISE) wherein measured hardness decreases with increasing indentation size. Different trends measured because of displacement, densification, deformations and frictional forces in the materials leads to an undeterminable indenter-depended microhardness measurement. The present study will investigate a crossover point for the different indenters at about the same indentation load between Vickers and Knoop indenters by measuring and Comparing of the Indentation Size Effect in Fused Silica and Crystalline Quartz. Also we calculated the ratio of the (surface area/indentation volume) from the geometries of the two indenters, which we believe is the explanation for the crossover.

\section{MATERIALS AND EXPERIMENTAL PROCEDURES}

Both the $7.5 \mathrm{~cm}$ diameter Fused Silica and the hexagon-shaped Crystalline Quartz which has $2 \mathrm{~cm}$ on each side tested in this study were commercially grown and obtained from Corning Tropel (Fairport, NY, USA), the (001) plane was ready to be tested. Both specimens were grown in the (001) and appeared fully transparent to the visible naked eye. A (001) plane of Crystalline Quartz was prepared for microhardness testing by polishing with successively finer abrasive and finally with $1 / 4 \mu \mathrm{m}$ diamond paste in a rotational polisher until the surface appeared to be smooth and scratch-free viewed under an optical microscope at $100 \times$. Both specimens were not annealed nor etched before or during testing period.

In this study, the direction specified for the microhardness is parallel to the long axis of the Knoop indenter and the mean diagonal length of the indentation impression of the Vicker indenter so that the risk for indentation cracking can be minimized, which results in the credibility of the hardness values. A goniometer was modified for installation on a Buehler Micromet 2004 Microhardness Machine to hold the crystals in position and to orient the crystals relative to both the Knoop and Vicker indenter for orientation with respect to the crystal directions on a specific crystal plane. The crystals were mounted on the goniometer using silly-putty and were insured that the crystal measurement surface was indented perpendicularly by the indenter during the testing by applying a simple hand press. Indention length measurements were made immediately from the impression after removal of the indenter. For the Knoop indenter, the microhardness values were determined from the length of the long axis of the indentation and the standard Knoop microhardness formula:

$$
\mathrm{H}_{\mathrm{k}}=14.230 \mathrm{P} / \mathrm{d}^{2}\left(\mathrm{kgf} / \mathrm{mm}^{2}\right) \text {, }
$$

where $\mathrm{P}$ is the indentation test load $(\mathrm{kg})$ and $\mathrm{d}$ is the long dimension of the Knoop impression (mm). While for the Vicker indenter the microhardness values were determined from the mean diagonal length of the indentation impression and the standard Vicker microhardness formula:

$$
\mathbf{H}_{\mathrm{v}}=1.854 \times \mathrm{P} / \mathrm{d}^{2}\left(\mathrm{kgf} / \mathrm{mm}^{2}\right),
$$

where $\mathrm{P}$ is the applied load $(\mathrm{kg})$ and $\mathrm{d}$ is the mean diagonal length of the indentation impression $(\mathrm{mm})$. For each of 


\section{Fused Silica microhardness}

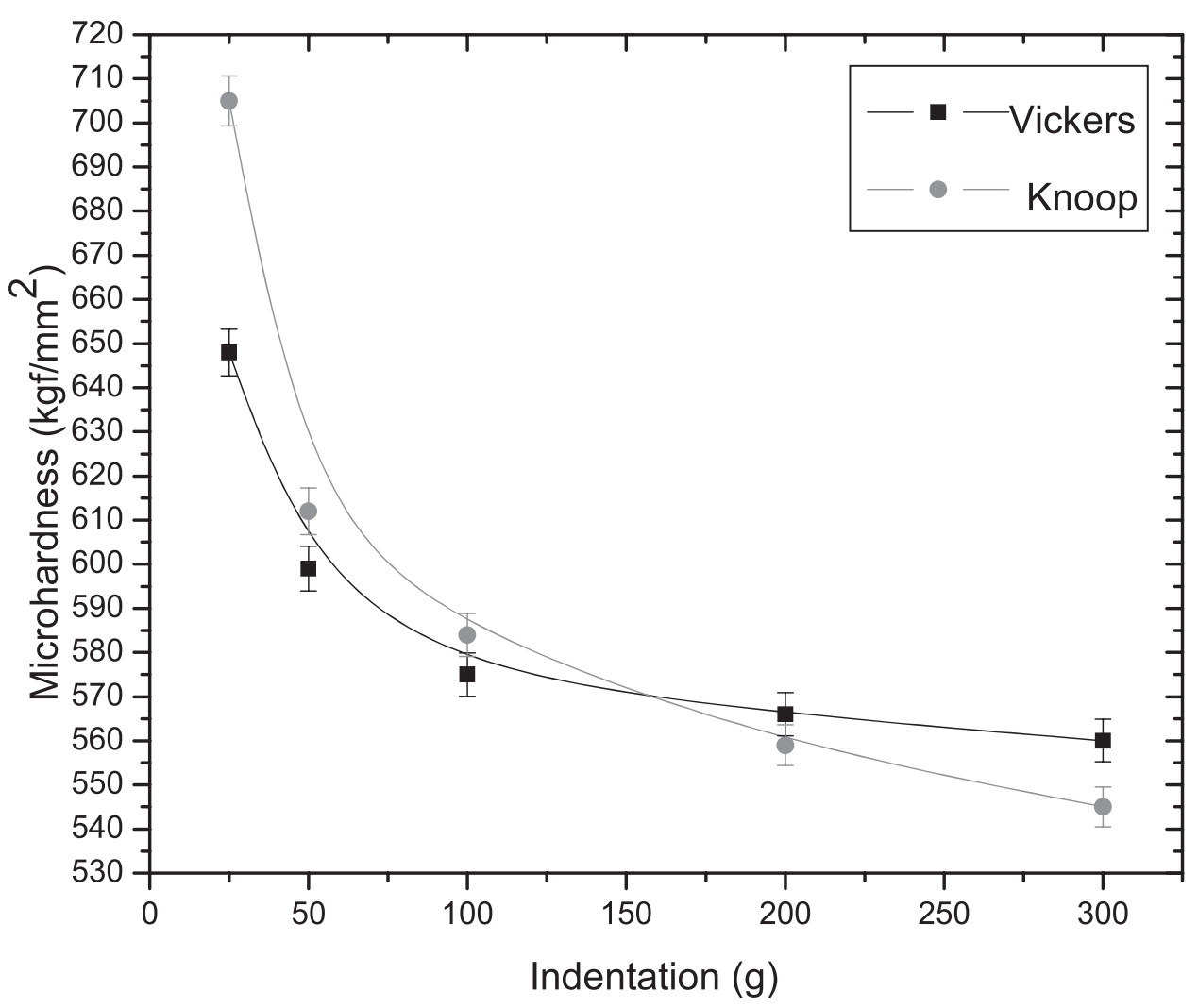

FIG. 1. (001) plane microhardness profiles, comparison of Knoop and Vicker indenters.

the reported microhardness values, 10 distinct, perfectly symmetrical and uncracked indentations were measured and their values averaged. Cracked indentations less than $3 \mathrm{~N}$ were rare for Fused Silica (Hamza et al. 2001).

\section{RESULTS AND DISCUSSIONS}

Figure 1 illustrating both Knoop and Vicker microhardness profiles on the (001) planes of the fused silica shows Indentation Size Effect (ISE) for both indenters which are consistent with those previously reported by Hirao and Tomozawa (1987) and Quinn, Green, and Xu (2003), and also a crossover is exhibited at $160 \mathrm{~g}$ indentation test load.

The profiles in Figures 2 and 3 exhibit the Indentation Size Effect (ISE) and microhardness anisotropy as previous reported for Quartz by Stevenson, Weaver and Bradt (2000). The figures also illustrate the crossovers at $160 \mathrm{~g}$ indentation test load as it does in Figure 1, which indicates that at one indentation test load the microhardness result does not depend on the Knoop or Vicker indenter. We calculated the ratio of the (surface area/indentation volume) from the geometries of the two indenters to explain this phenomenon since microhardness is reported to associate with surface energy. The ratio for the Knoop indenter is 3.3606/t, while the ratio for Vicker indenter is $3.2356 / \mathrm{t}$, which indicates both ratios only depend on the depth of the indenter in the tested specimen, t. Thus it is possible for both Knoop and Vicker indenters, to reach one common surface area/ indentation volume ratio which might lead to the same measured value.

\section{SUMMARY AND CONCLUSIONS}

The Indentation Size Effect (ISE) was measured for the (001) planes of Fused Silica and Crystalline Quartz with two directions. The ISE profiles are consistent with previously reported and microhardness anisotropy profiles for Crystalline Quartz. Also a common crossover for both Fused Silica and Crystalline Quartz was discussed and a possible explanation was given.

Acknowledgments: We are grateful to Corning Tropel for supplying the Fused Silica and the hexagon-shaped Crystalline Quartz that were measured. The financial support of L. Zhang for summer research by NSF\# 0907673, for which V. Acoff and M. Weaver were co-PI's. 


\section{Quartz [1010] microhardness}

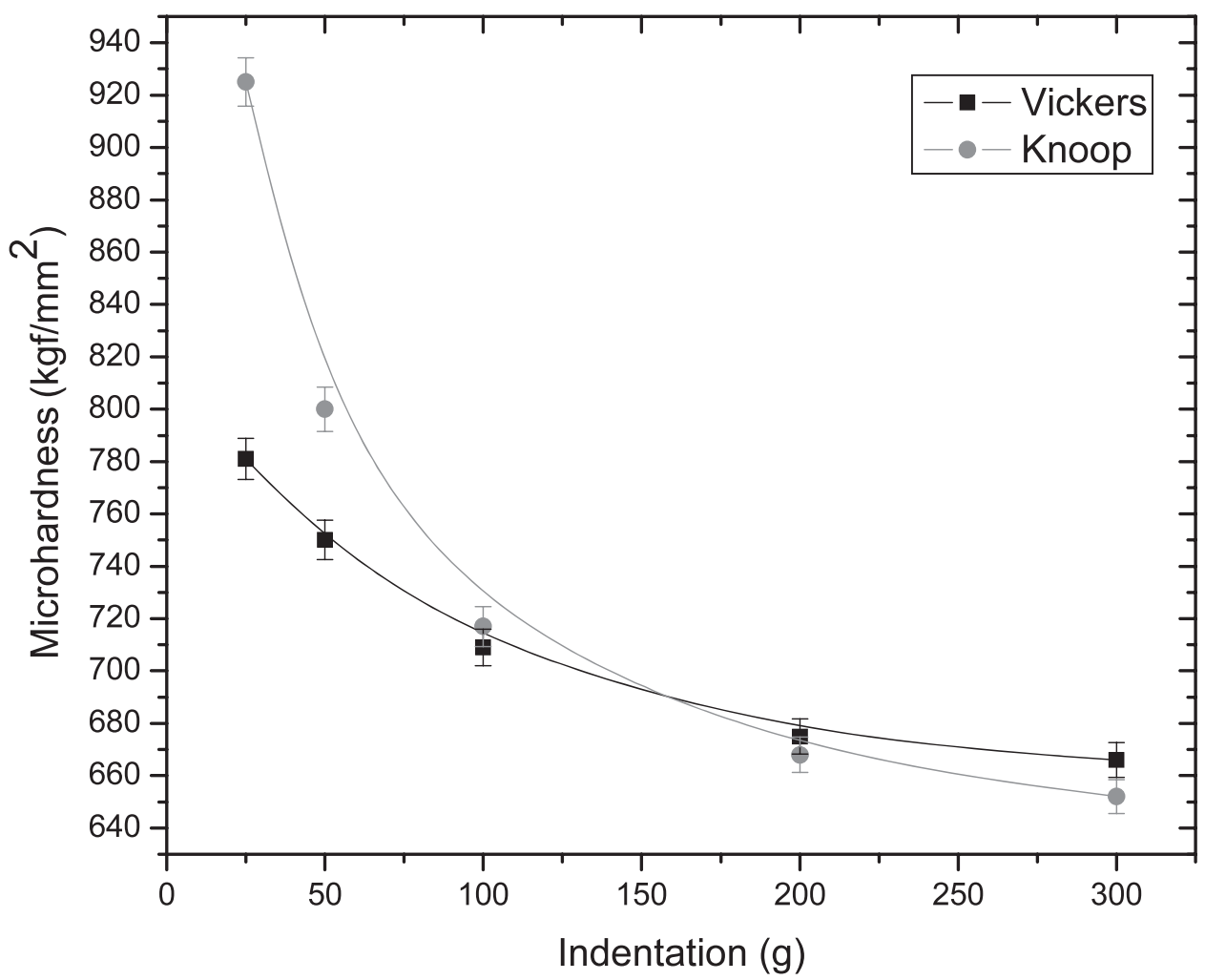

FIG. 2. (001) plane [1010] direction microhardness profiles, comparison of Knoop and Vicker indenters.

\section{Quartz [2110] microhardness}

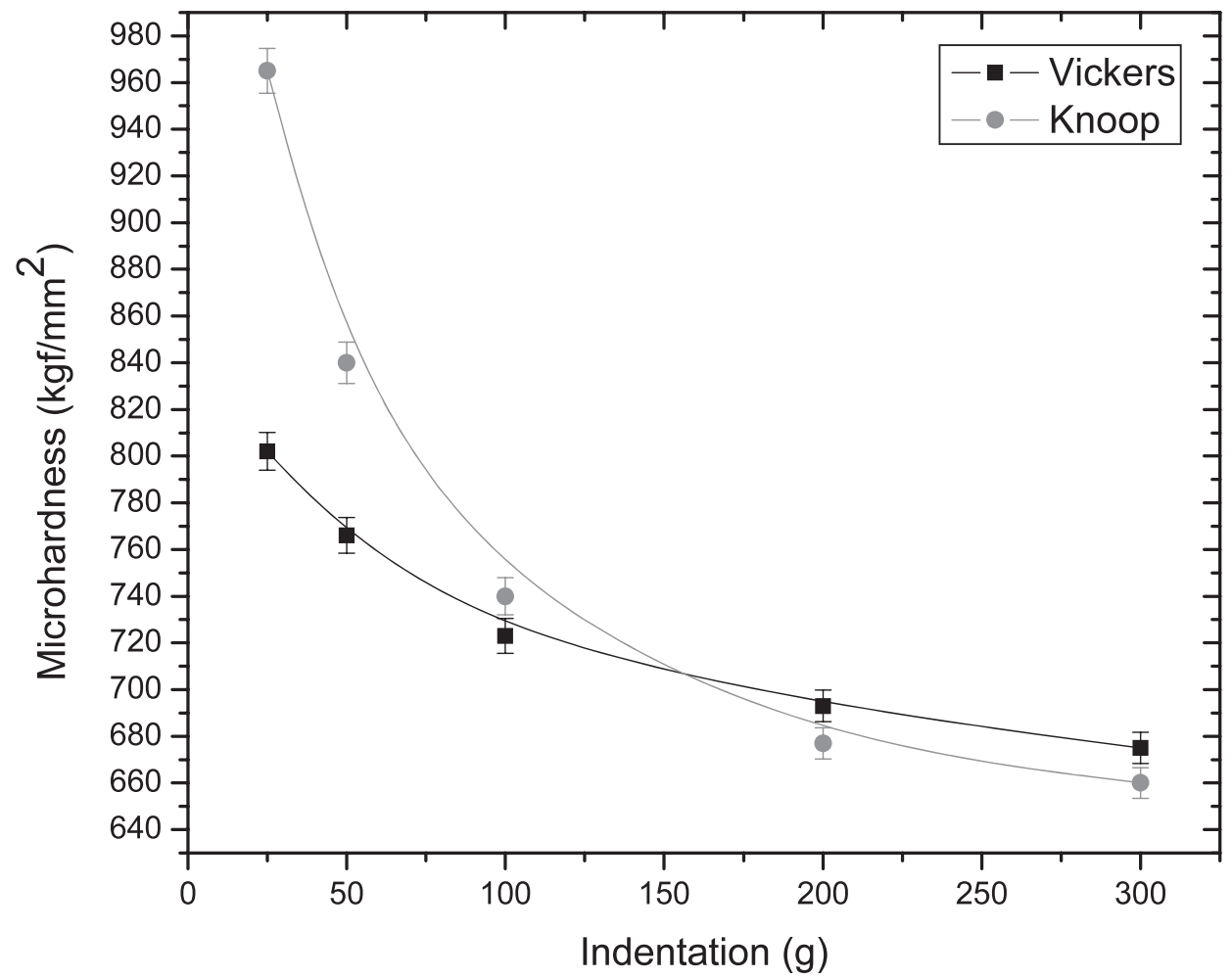

FIG. 3. (001) plane [2110] direction microhardness profiles, comparison of Knoop and Vicker indenters. 


\section{LITERATURE CITED}

HAMZA, A. V, ET AL. 2001. Engineered defects for investigation of Laser-induced damage of fused silica at $355 \mathrm{~nm}$. XXXIII Annual Symposium on Optical Materials for High Powered Laser Boulder Damage Symposium, Boulder, Colorado, October 1-3. BERKOVICH, E. S. 1951. Ind. Diamond Rev. 11:129-132.

BLAU, P. J., AND B. R. LAWN. 1986. Microindentation techniques in materials science and engineering. STP 889; Philadelphia, PA, ASTM.

GEORGE, D. QUINN, PATRICE GREEN, AND KANG XU. 2000. Cracking and the Indentation Size Effect for Knoop Hardness of Glasses. J. Amer. Ceramic Soc. 86(3):441-448.

LYSAGHT, V. E. 1949. Indentation hardness testing, New York. Reinhold.
KAZUYUKI HIRAO, AND MINORU TOMOZAWA. 1987. Microhardness of $\mathrm{SiO}_{2}$ Glass in Various Environments. J. Amer. Ceramic Soc. 70(7):497-502.

STEVENSON, M. E., M. L. WEAVER, AND R. C. BRADT. 2000. Microhardness Anisotropy and the Indentation Size Effect (ISE) on the (100) of Single Crystal NiAl. MRS Fall Meeting.

MOTT, B. W. 1957. Microindentation hardness testing. London, Butterworths.

O'NEILL, H. 1967. Hardness measurement of metals and alloys. London, Chapman and Hall.

TABOR, D. 1951. The hardness of metals. Oxford, Clarendon Press. WESTBROOK, J. H., AND H. CONRAD. 1973. The science of hardness and its research applications. Metals Park, OH, ASM. 